\title{
Influence of Cutting Conditions on Chip Formation When Turning ASSAB DF-3 Hardened Tool Steel
}

\author{
Adam Umar Alkali, Noordin Mohd Yusof, Mohamed Handawi Sa'ad Elmunafi, and Hasan Fawad
}

\begin{abstract}
Machining investigations were made on ASSAB DF-3 oil hardened tool steel HRC 45 using wiper coated ceramic tool. Both cutting speed and feed rates were purposely and continually changed to enable investigations performed at various cutting combination. Both cutting speed and feedrate were found to influence the formation of saw tooth shape on the chip from a non-saw tooth shape. The chip forms collected were observed using digital camera and optical microscope and were studied in terms of their form, thickness and micro hardness. The saw- tooth chip obtained in this study was a result of some interrelated mechanisms such as localized shear, adiabatic shear and also as a catastrophic shear in the form of extensive cracks. A relationship was established between the chip geometry and the cutting conditions.
\end{abstract}

Index Terms-Chip, cutting speed, feed rate, and saw tooth.

\section{INTRODUCTION}

The intricacy connected with the hard turning process from a material deformation and chip formation standpoint is yet meagerly documented. Particularly, comprehending chip formation is crucial considering that it influences the selection of the material grade of the cutting tool along with workpiece quality related factors like residual stresses as well as white layer formation relating to the machined work surface. Significant consideration ought to be presented to chip control because of its growing benefits in underlying effective machinability. A useful hypothesis reported in [1] on chip formation in turning being a result from crack initiation was an impulse to us for further investigation. Further clarification in [2] emphasized the influences of cutting speed to the formation of chips. The present study revealed the effect of feedrate as another factor of consideration in chip formation while turning hardened materials. Recent study [3] presented the relationship between the chip geometry, the cutting conditions and varying micrographs at different metallurgical states.

This study is however, aimed at obtaining the chips resulting from varying cutting conditions that has been carried out during the machining test and evaluating same by way of examining the mechanism involved during the formation of the chips.

Manuscript received November 10, 2012; revised January 5, 2013. Adam Umar Alkali and Hasan Fawad Junejo are with the Department of Mechanical Engineering at the Universiti Technologi PETRONAS, Malaysia (email: adamu_g01876@petronas.edu.my).

Noordin Mohd. Yusof is with the Department of Manufacturing and Industrial Engineering, Faculty of Mechanical Engineering, Universiti Teknologi Malaysia (UTM), Skudai, Johor.

Mohamed Handawi Sa'ad Elmunafi is with the Department of Mechanical Engineering at the University Technology Malaysia.

\section{TOOL AND WORKPIECE MATERIAL}

\section{A. Workpiece Material}

ASSAB DF-3 (cylindrical bar) through hardened tool steel was used as the workpiece material. DF-3 general purpose oil hardened tool steel is a versatile manganese-chromium -tungsten steel suitable for a wide variety of cold-work applications. DF3 tool steel influenced a choice for this study because of its good machinability, good dimensional stability in hardened state, good combination of high surface hardness and toughness after hardening and tempering.

\section{B. Cutting Tool Material}

A rhomboid shaped coated wiper ceramic tool from Kennametal was used for the machining test. The inserts was ANSI coded CNGA 120412EFW, and has a tool nose radius $(\mathrm{r} \varepsilon)$ of $1.2 \mathrm{~mm}$. The ceramic tool was mounted on left corner tool holder that was geometrically coded Kennametal MCLNL 16161412.

The cutting tool has the following geometry;

Side rake angle $\gamma=-5^{\circ}$

Back rake angle $\alpha=-5^{\circ}$

Side cutting edge $($ SCEA $)=-5^{\circ}$

Nose radius $r=1.2 \mathrm{~mm}$

\section{EXPERIMENTAL SETUP}

The workpiece was machined on the faces to obtain a proper shaped facial area. The workpiece was center drilled at both ends to enable support between centers both in order to minimize vibration as well as impact of forces resulting from the material removal. Cutting tool was mounted and securely held in position and aligned with the workpiece at both $X$ and $Z$ coordinates being reference for the machine set up. A chamfer was made at the end of the workpiece to facilitate tool entry.

The chip specimens were prepared for microscopic examination. Collected chips were mounted, hand grinded with little caution using sand paper of various grades, typical are 230,320, 500, 1000 and 1200 in order. The specimens were manually polished with aid of alumina paste and were later etched. Etching is performed with controlled preferential attack on the metal surface in order to reveal available microstructural details. Villella's reagent was used with the composition of $1 \mathrm{~g}$ Picric acid, $5 \mathrm{ml} \mathrm{HCL}$ and $100 \mathrm{ml}$ of ethanol. The typical exercise was to dip the prepared chips into the etchant for between 5 to 10 seconds, followed by washing with flowing water, then drying using hot air. The structure obtained enables us to evaluate the flow of the chip grain structures and also to determine the shape of the chips under microscopic view. 


\section{RESULT AND DISCUSSION}

Fig. 1 shows chip forms obtained at different cutting conditions. Basically, the chip forms were a snarled washer type helical chip despite having been obtained at various cutting speed and feed rates. This was attributed to be due to the constant and low depth of cut that was used throughout. Various combination of cutting speed and feed had been investigated. The chips obtained were basically continuous chips and was possibly influenced by the stress, strain, and temperature gradients which remained constant with respect to time; that is to say, a steady-state condition is reached. Rao [4] attributed some ideal conditions that promote continuous chips in metal cutting which includes sharp cutting edge, small chip thickness (fine feed), large rake angle, high cutting speed, ductile work materials and less friction between the chip tool interface through efficient lubrications' Continuous chips are usually the most useful chips because the work surface finish attained is usually routinely effective and smooth. It also helps in having prolonged tool life and lower power consumption. However, it was observed during this study, that at higher cutting speed, the surface finish was also better and that the surface finish improves as the cutting speed increases from $100 \mathrm{~m} / \mathrm{min}$ to $210 \mathrm{~m} / \mathrm{min}$. Fig. 2 below demonstrated the surface finish obtained at varying conditions of the chip form obtained.
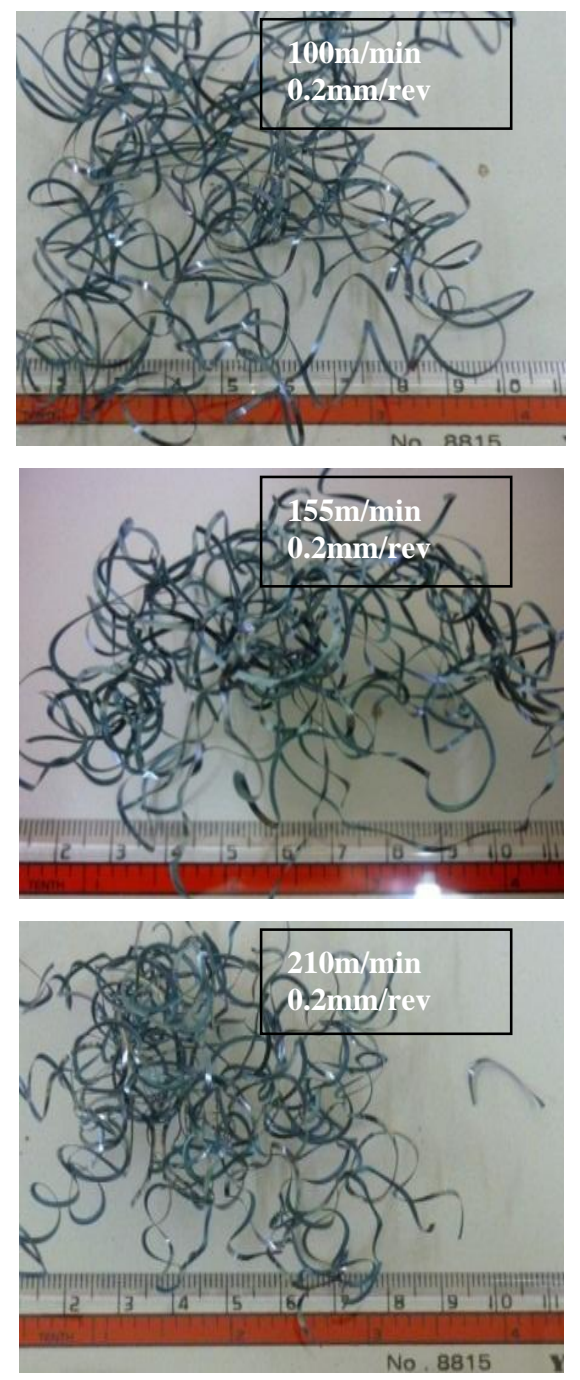

Fig. 1. Physical appearance of chip form at various cutting conditions while cutting ASSAB DF -3 tool steel.

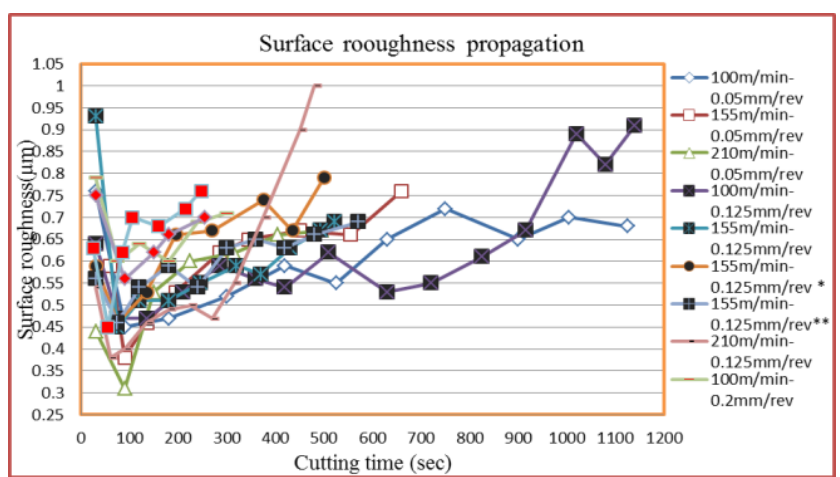

Fig. 2. Surface roughness propagation when turning hardened tool steel with KY 4400 wiper inserts.

\section{CHIPS MICROGRAPHS}

It was observed that there was no significant change in the shape of the chip at lower cutting speed and feedrate. However jagged saw teeth edges shapes were noticed at lower feed rates than higher feedrate. Illustrated in Fig. 3, the saw tooth edge chip form was evidently influenced at cutting speed of $210 \mathrm{~m} / \mathrm{min}$ and $0.05 \mathrm{~mm} / \mathrm{rev}$ and tend to diminishes with increase in feed rate as it changes to $0.2 \mathrm{~mm} / \mathrm{rev}$ through $0.125 \mathrm{~mm} / \mathrm{rev}$. This transition is the result of a thermoplastic instability in the shear zone. Some trend was observed in the thickness of the sample where chips thickness was influenced by both the cutting speed and feedrate alike. At cutting speed of $210 \mathrm{~m} / \mathrm{min}$ and feedrate $0.05 \mathrm{~mm} / \mathrm{rev}$, the thickness recorded was up to $197.8 \mathrm{um}$ as measured with optical microscope attached with image analyzer. The thickness decreases with corresponding increase of the feedrate. Hence higher thickness reading was observed at higher cutting speed which also decreases as the cutting speed drops. The transition from non sawtooth chip formation to sawtooth chip formation is effected by an increase in cutting speed and feed [5]. Thus either cutting speed or feedrate could influence the formation of saw tooth shape on the chip from a non-saw tooth shape. Fig. 3 shows the image of all the chips sampled from the cutting conditions investigated in this study.

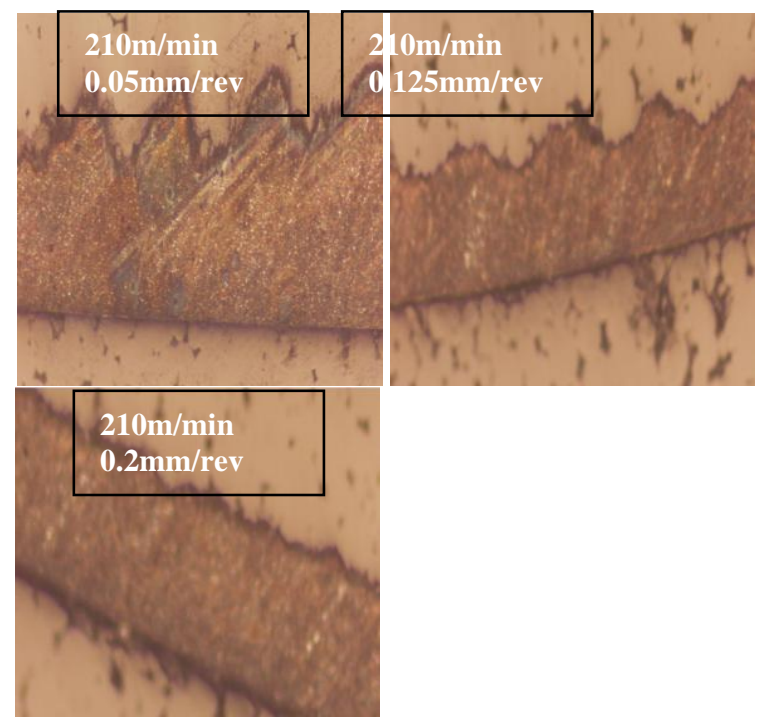

Fig. 3. Micrographs of post-process chip form for various cutting condition using wiper coated ceramic tool. 


\section{CHIP THICKNESS}

From Fig. 4, it was found that the chip thickness tends to decrease as the cutting speed decreases for all of the feed investigated. However, the value of average chip thickness also decreases as the feed decreases. Hence, the feed rate influences the thickness of the chip as the cutting speed does. As reported by [5] this is due to the increase in the undeformed chip thickness with increasing feed and the tangential force is proportional to the undeformed chip thickness as this increase will result in an increase in shear plane area.

Similar to [6], when the cutting force decreases, the deformed chip thickness also decrease. This happened when the force $\mathrm{Fc}$ acts downward on the tool tip and tends to deflect the tool downward. This force is that which supplies the energy required for the cutting operation. It is assumed that as the chip thickness decreases so also does the power consumption of the machine, owing to low chip thickness during chip removal. At this same time less vibration was observed and surface roughness improves.

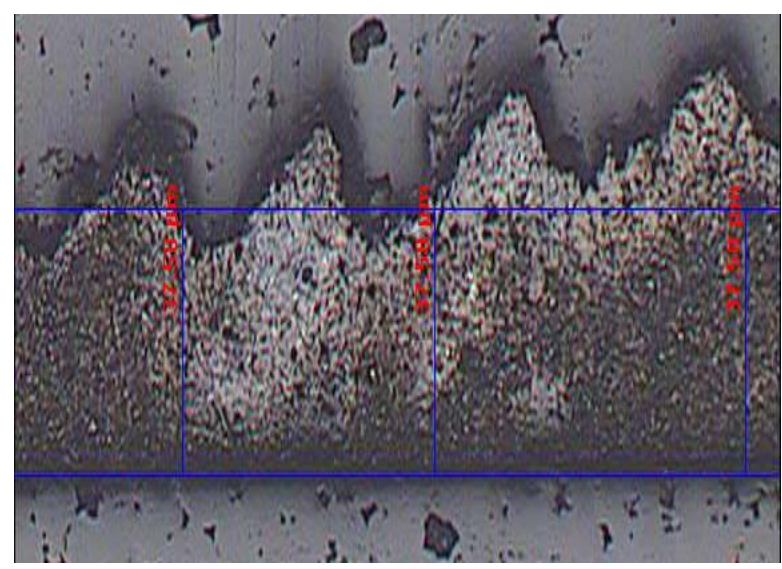

Fig. 4. An Average chip thickness measured 197.88um while cutting at $210 \mathrm{~m} / \mathrm{min}$ and $0.05 \mathrm{~mm} / \mathrm{rev}$ using wiper coated ceramic tool.

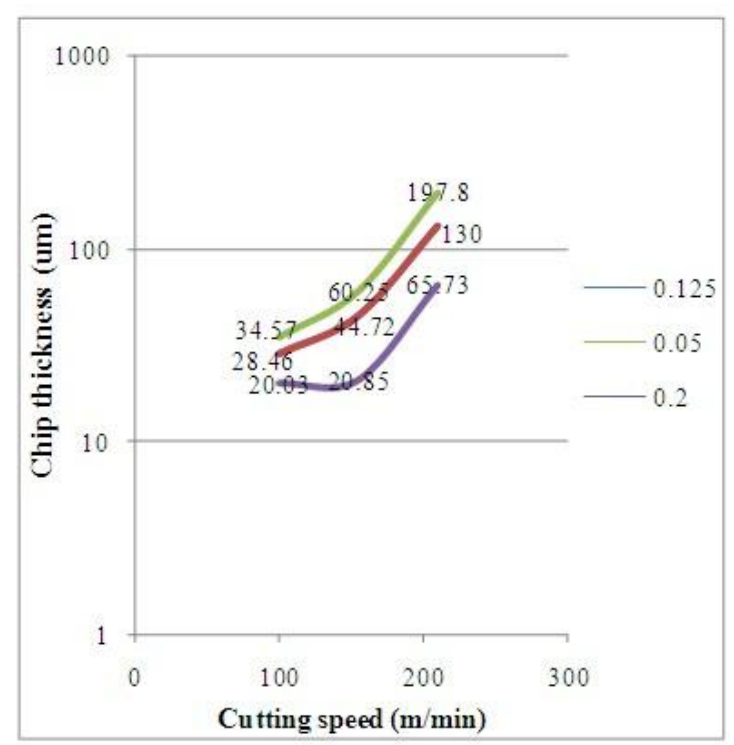

Fig. 5. Chip thickness and cutting speed relationship at (a) $0.2 \mathrm{~mm} / \mathrm{rev}$. (b) $0.125 \mathrm{~mm} / \mathrm{rev}$. (c) $0.05 \mathrm{~mm} / \mathrm{rev}$.

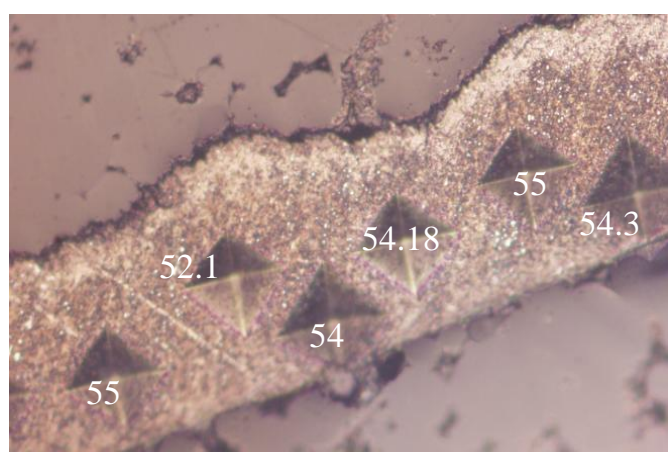

Fig. 6. A Micrograph of the Micro indentation of a chip saw tooth shaped specimen obtained after cutting at $100 \mathrm{~m} / \mathrm{min}$ and $0.125 \mathrm{~mm} / \mathrm{rev}$.

\section{MiCROHARDNESS OF THE CHIPS}

Relative decrease of the average hardness of chips with increasing cutting speed was observed. Micro hardnesses obtained were in the range of $52-55 \mathrm{HRC}$. The micro hardness readings obtained were basically higher than those obtained on the machined workpiece material. [7] Attributed the hardness change of the turned surface to extremely small grain size and high dislocation density as well as re-quenched martensite.

\section{CONCLUSION}

Continuous chips were obtained for all the cutting conditions investigated. It was further found out that jagged saw teeth edges shapes were noticed at lower feed rates than at higher feeds and it tends to diminish with increase in feed rate as it changes from $0.05 \mathrm{~mm} / \mathrm{rev}$ to $0.125 \mathrm{~mm} / \mathrm{rev}$.

The experiment also found that the chip thickness tends to decrease as the cutting speed decreases for all of the feedrate investigated. Generally, the findings of this study concluded that both cutting speed and feedrate are found to have an effect on the thickness of the chip produced. However, an increase in cutting speed will decrease the force component values which eventually improve the surface roughness value and this was attributed to the reduction of chips to a thinner thickness. Continuous chips were obtained for all the cutting conditions investigated wherein saw tooth shaped was influenced by both the cutting speed and the feed rate alike.

\section{REFERENCES}

[1] M. A. Elbestawi, A. K. Srivastava, and T. I. E. Wardany, "A model for chip formation during machining of hardened steel," Annals of the ClRP, vol. 45, July 1996.

[2] M. C. Shaw and A. Vyas, "The mechanism of chip formation with hard turning steel," Annals of the ClRP, vol. 47, January 1998.

[3] S. B. Salem, E. Bayraktar, M. Boujelbene, and D. Katundi, "Effect of cutting parameters on chips formation in orthogonal cutting," Journal of Achievements in Materials and manufacturing Engineering, vol. 20, issue 1, 2012.

[4] P. N. Rao, Manufacturing technology metal cutting and machine tools, Tata McGraw Hill, vol. 33, no. 35, pp. 5-10, 2000.

[5] M. Y. Noordin, "Performance evaluation of coated carbide and coated cermet tools when turning hardened tool steel," Ph.D. dissertation, Dept. Mech. Eng., Universiti Teknologi Malaysia., Malaysia, 2004.

[6] S. Kalpakjian and S. R. Schmid, Manufacturing processes for engineering materials, Fourth Edition, Preintice Hall, pp. 464-527. 2003. 
[7] Y. B. Guo and J. Sahni, "A comparative study of hard turned and cylindrically ground white layers," International Journal of Machine Tools and Manufacture, pp. 135-145, 2004.

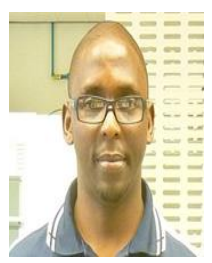

Adam Umar Alkali was born in the ancient city of Kano state in the Northern part of Nigeria. Currently a Ph.D. research student in the Department of Mechanical Engineering at the Universiti Technologi PETRONAS, Malaysia. He obtained his Master Degree in Advanced Manufacturing Technologi from Universiti Technologi Malaysia (UTM), Malaysia. Earlier study included Bayero University Kano, Nigeria, Kaduna Polytechnic Kaduna Nigeria, and Kano State Polytechnic - Kano Nigeria, for the Undergraduate qualifications in Mechanical - Production Engineering. He taught various engineering courses at Diploma and Higher national Diploma level at Polytechnic level. He is currently pursuing his $\mathrm{PhD}$ under a graduate assistant scheme in the University Technology Petronas in Malaysia. Alkal is currently an applicant for membership of Nigerian society of engineers and Nigerian institute of mechanical engineers.

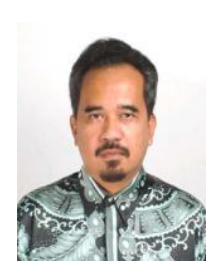

Noordin Mohd. Yusof is a professor at the Department of Manufacturing and Industrial Engineering, Faculty of Mechanical Engineering, Universiti Teknologi Malaysia (UTM), Skudai, Johor. He earned his B. Mech. Eng. (Hons) and Ph.D. in Mechanical Engineering from UTM and M. Sc. (Advanced Manufacturing Technology) from Cranfield Institute of Technology, U.K. Prior to joining the university in 1987; he worked in Harris Semiconductor Malaysia and Matshushita Industrial Corporation in the Quality and Production Engineering departments respectively. He has conducted and supervised numerous research projects on machinability studies, sustainability, statistical quality control, maintenance and membrane manufacture. $\mathrm{He}$ has published and presented his works at various international and national seminar/conferences on the above subject matters. Additionally, he has also published papers in various national and international scientific journals. Profesor Noordin has held various administrative positions in UTM. He is currently the Deputy Dean (Development) at the Faculty of Mechanical Engineering.

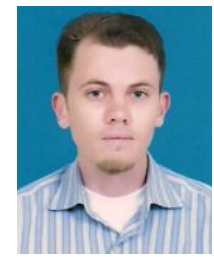

Mohamed Handawi Sa'ad Elmunafi was born in Benghazi - Libya. He was born on 3rd of August 1980. Currently a Ph.D. research student in the department of Mechanical Engineering at the University Technology Malaysia. He obtained his master degree in Advanced Manufacturing Technology from universiti technologi Malaysia (UTM). Earlier he studied at Garyounis University in Benghazi where he studied industrial and manufacturing engineering department.

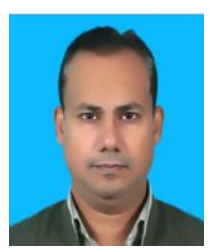

Hasan Fawad Junejo is senior lecturer at MED UTP. $\mathrm{He}$ has earned Ph.D. in Advance manufacturing from Ghulam Ishaq Khan Institute Pakistan in 2006. He has authored 24 international journal and conference papers in the area manufacturing and computational heat transfer. Dr. Hasan completed his Masters in nuclear power and BE in Mechanical engineering from NED university Pakistan in 1997 and 1995 respectively. Prior to joining UTP Dr. Fawad was working with Ghulam Ishaq Khan institute(2009-2011) as Assistant Professor and Pakistan Atomic energy comm.(1997-2009) as principal engineer. 